\title{
Our legal heritage at risk: rescuing private sector legal records
}

\author{
Clare Cowling, Director, Legal Records at Risk project, IALS
}

\section{What is the Legal Records at Risk project?}

In September of 2015 the Institute for Advanced Legal Studies launched the Legal Records at Risk project in response to a growing crisis of legal records management in the UK. The crisis has arisen from a number of different factors, ranging from globalisation and new developments which have changed the nature of legal services to more practical issues such as digital continuity problems and the lack of space or suitable conditions for document storage. Though largely overlooked, this represents a profound loss of both a valuable legal and scholarly resource, and also a significant part of our legal heritage.

Since its launch, the objectives of the Legal Records at Risk Project have been:

1. To broaden the concept of "legal" records from their traditional definition as court records or deeds to the records of private sector institutions specialised to law (ISLS), including: arbitration and mediation services; barristers; solicitors; insolvency practitioners; legal executives; licensed conveyancers; multi-disciplinary practices; notaries; patent attorneys; pro bono legal services; scriveners; trade mark attorneys and providers of ancillary services such as law publishers and legal stationers.

2. To raise awareness of researchers in all disciplines of the importance of private sector institutions specialised to law in the development of the United Kingdom's legal framework and of the need to preserve records of value not only to demonstrate these changes in our legal history but for a variety of other research fields such as sociology, biography, economics, geography, class, race and gender.

3. To assist the information owners of private sector legal records in recognising the value of their records and unlocking the potential of the records for both internal business reference and external research use, facilitating a better understanding of the importance of private sector ISLs in the development of the UK's legal and business framework.

In the six months since the project commenced, we have contacted representatives from the key groups relevant to the project - archivists, legal practitioners and researchers, and have discovered a wide variety of records at risk, discrepancies in understanding the issues involved and disparate efforts to rescue selected records.

\section{What categories of legal records are at risk?}

The largest category of legal records currently under threat consists of those from the private sector. These are frequently at risk of becoming lost or inaccessible through globalization, digital obsolescence, and physical neglect, as well as lack of interest on the part of information owners combined with reduced archive resources to preserve and provide access to the records. All records in the UK in the private sector face similar challenges, but modern legal records (C20-C21) are particularly vulnerable due to recent developments which are transforming the nature, organisation, regulation and economics of legal services, often in unpredictable ways. These 
changes are outstripping the capacity of the traditional providers of legal research facilities to make relevant records available.

There are upward of 100 "business" archives in the UK, dominated by banking, the alcohol trade and retail - there are no "legal" archives other than the Inns of Court archives, the small archive of The Law Society and the Records of Legal Education Archives at IALS. Unless systematic efforts are made towards collecting private sector legal records, modern legal research will continue to be weighted towards the study of records of the courts, producing a lopsided picture of the UK's legal framework and of the legal practitioner's role as an integral part of UK business.

There are numerous legal records at risk which the project seeks to rescue, but at the time of writing there are three categories of records about which the project has particular concerns:

1. Solicitors' records:

The Law Society (TLS), working with the Selden Society, has for many years encouraged solicitors to seek options for the preservation of their firms' historically significant legal documents. TLS's practice note Depositing records and documents with public sector archives (15 December 2010 - see lawsociety.org.uk/support-services/advice/practice-notes/depositingrecords-files/) provides advice on depositing old client documents or older records documenting a firm's history with the appropriate local authority record office. Many records offices, however, are now operating on severely reduced resources, compromising their ability to accept private sector records.

The Solicitors' Regulation Authority manages a vast archive of the records of intervened law firms. Without expert help and advice it is unlikely to be able to identify and extract records of potential research value when disposing of the bulk of this material.

The British Records Association, which used to act as a warehousing facility while arranging the transfer of records to archives offices, no longer has the capacity to provide the storage service.

Solicitors' records are, therefore, more at risk now than in the past.

2. Alternative dispute resolution (ADR) records:

The development of ADR reflects the momentous changes in the UK's legal framework, yet records available for research into these developments are patchy and random at best. While arbitration, adjudication, mediation and conciliation records will be found in the archives of some businesses and government organisations and some higher education archives and libraries may collect some ADR records of relevance to their particular collections policy, there is no archive in the UK specifically dedicated to these records.

It appears from our preliminary investigations that research into this field of law has been largely confined to using secondary source material - possibly because of the difficulties in locating primary source documents. If primary source ADR records are not identified and saved for posterity we will lose an integral part of our legal heritage.

3. Born-digital legal records:

The issue around preserving and providing long-term access to born-digital records is in no way confined to legal material; digital continuity and obsolescence are major problems for all institutions. The National Archives is managing the issue on behalf of government bodies, but private sector organisations will have to find their own solutions. 
Many legal records which require long-term retention for business reasons (such as client files) are now created and managed digitally, yet little or no thought has been put into digital continuity - in other words, their accessibility over time. There is a great deal of generic advice readily available, yet the financial investment necessary to ensure digital continuity is still not seen as an essential component of modern legal business. In the long term this means that there will be few or no records available in the future for research other than from the public sector.

\section{How will the Legal Records at Risk project mitigate this risk?}

The project will not collect records but will act as a conduit through which legal records of value (in all formats and media) are identified, preserved and made available for research. In doing so we hope to:

1. Identify and facilitate the rescue of legal records of potential value by developing a costeffective and coordinated process for the transfer of records (in both hard copy and digital format) to appropriate repositories and by advising on digital continuity.

2. Broaden the perspective of legal research, which has hitherto been primarily concerned with investigating the pre $\mathrm{C} 20$ records of the courts. We wish to widen the use of C20 and C21 legal records in particular by demonstrating their relevance to a number of research disciplines. Our investigations to date into the primary use of "legal" records in archive repositories (usually narrowly defined as deeds or court records) shows it to be genealogical. Is this a missed opportunity for academic research or a reflection of the lack of variety and diversity in legal records readily available for research or both?

\section{How will we achieve these objectives?}

The Legal Records at Risk project aims to advance its objectives by undertaking a range of collaborative efforts with the legal community, engaging researchers, archives, legal professionals and ISLs. In doing so, we aim to also provide a range of services to these communities. This includes:

- Creating a census of private sector ISLs in England and Wales, with details of what, if any, provision has been made to preserve their archives.

- Identifying legal records of research value and relevant repositories.

- Facilitating the process by which information owners deposit with or donate records to repositories.

- Providing generic recordkeeping advice to information owners.

- Recognising and advocating best practice.

- Building on and taking forward, in collaboration with the Business Archives Council, the British Records Association, The National Archives and others the valuable work already done to identify and save private sector records at risk by a) devising a co-ordinated strategy for the identification and preservation of records of value, including legal records and $b$ ) developing a digital records rescue and continuity framework.

- Working with research communities to identify their needs. 


\section{How can SALS members help?}

The ultimate success of the Legal Records at Risk project relies heavily on the active involvement of organisations and individuals from within the legal community. There is, therefore, a pressing need to foster greater collaboration with lawyers, legal scholars, ISLs and others involved in the practice and study of law.

The Legal Records at Risk project has a particular need for greater involvement from professionals involved directly in the practice of law. To date there has been an imbalance in the response to the project between archives and researchers, and the legal profession. Without involvement from the latter, researchers will face a huge gap in material available from which to study the rapid changes to our legal services over the past century. This gap will widen exponentially as almost all records are now created and managed digitally, yet digital continuity and obsolescence is not on the radar of most ISLs nor even of many research institutions and archives.

We therefore need:

- Legal champions and representatives of the legal community to collaborate with us, and to help spread awareness of the project.

- Legal information owners to contact us in order to outline the issues they may be facing in managing and disposing of information. We also invite information owners to ask us for advice on particular challenges such as digital continuity, to seek guidance on how to identify records of value both for business use for external research, and to request contacts to relevant archival repositories.

- Legal researchers to advise on their research requirements, to ask for help in locating potential archive repositories and records, and to suggest ways to make legal records already held in archives more accessible.

\section{What are the long-term goals of the project?}

- Our primary goal is to change the culture surrounding the perception of what legal records actually are and to facilitate their use in academic research. In doing so we hope to enhance the relationship between legal practitioners, researchers and archivists.

- We seek, through the above, to rescue specific legal records of research value which are or may be at risk and to co-ordinate their deposit in an appropriate archive repository.

- We also intend to produce a short book describing the project, outlining its methodology and its successes and failures. The book will include a number of case studies into the records and record keeping of specific ISLs and into collections of legal records - and their reference use held in business and higher education archives.

The project is being led by Clare Cowling, an experienced archivist and records manager. You can contact her at clare.cowling@sas.ac.uk. For the latest project news see our website: ials.sas.ac.uk/research/Irar/Irar.htm, which includes details of our introductory seminar/workshop. Further workshops are planned. 